\title{
Methodology for making decisions in managing commercial real estate
}

\author{
Denis Smirnov ${ }^{1}$, Irina Alpackaya ${ }^{2, *}$, Taisiya Ryabova $^{1}$, and Valery Gusev ${ }^{1}$ \\ ${ }^{1}$ K.G. Razumovsky Moscow State University of Technologies and Management (the First Cossack \\ University) Zemlyanoy Val St, 73 Moscow, 109004, Russia \\ ${ }^{2}$ Moscow State University of Civil Engineering, 26, Yaroslavskoe shosse, Moscow, 129337, Russia
}

\begin{abstract}
The purpose of this paper is to develop guidelines for the formation and implementation of a decision-making mechanism for managing commercial real estate. As a result of the study, the current trends in the development of the real estate market are revealed, the methods and established practice of the activities of management companies are analyzed, the analysis of theoretical approaches to the management of commercial real estate is carried out. On the basis of theoretical and methodological principles and the specifics of the analyzed area of research, methodological recommendations are proposed for the formation of a mechanism for managing commercial real estate, including a method for assessing their investment attractiveness.
\end{abstract}

\section{Introduction}

Nowadays, the real estate management system has not yet passed the initial stage of its formation. There is a lack of structured knowledge on this topic; there are no methods regulating professional activities in real estate management; there are difficulties in attracting highly qualified specialists; there are almost no systems for training and retraining personnel. These problems are posed most acutely in the field of commercial real estate. The evolution of market processes in the field of real estate and systems for managing these processes did not give the commercial real estate market a leading position. However, the growing dynamics of demand for commercial real estate and the need for the reconstruction of commercial real estate, its productive use determine the special significance of this problem. There is an obvious need to develop management tools that can radically change the spontaneously developing process of transforming commercial real estate based on the real interests of the owners.

As a socio-economic reality, the real estate market can be characterized from various positions. From a governance perspective, the real estate market is a set of mechanisms through which property rights and related interests are transferred, prices are set, and space is allocated between various competing land-use options.

By functional purpose, the real estate market is divided into three components: the land market, the housing market, and the non-residential market. The latter includes the

\footnotetext{
* Corresponding author: alpackaya-irina@mail.ru
} 
industrial real estate market, as well as the markets for offices, retail and warehouse premises [1].

The commercial real estate market is actively developing, but this development is accompanied by a number of problems. These include: unprepared premises for rent; limited choice of premises, lack of floor space, etc. The solution to these problems can be found on the basis of the introduction of special management technologies, which should be used in the transformation of commercial real estate in order to harmonize the interests of owners and tenants - users of specific objects.

\section{Materials and Methods}

The development of the real estate market has led to the emergence of a specific type of entrepreneurial activity - professional property management. The objective prerequisites for this process are:

- growth in the scale of real estate involved in economic turnover;

- heterogeneity of the composition of property complexes;

- the owners are aware of the complexity of management and the need to attract specialists in the field of solving management problems for the use and transformation of commercial real estate.

One of the ways to manage the property is to hire a professional property management company. Using the services of a management company (as shown by foreign and domestic experience) is highly advisable, since full-fledged real estate management requires combining the efforts of specialists from different areas, who are concentrated in management companies.

The list of services offered by modern management companies is very extensive. It has long stepped over the scope of maintenance services and standard brokerage services and includes a set of independent activities and management procedures in the field of consulting, marketing research, investment analysis, assessment, and management practice. One of the main problems in the activities of professional management companies is the underestimation by many property owners of the resources embedded in real estate objects that do not perform professional tasks. Often, professional managers are approached only at the time of crisis situations, when an enterprise is on the verge of bankruptcy or income from its core activities is barely enough to cover the costs of maintaining the property complex, re-profiling the territories and facilities located on them. In this case, the activity of professional managers is a kind of anti-crisis management. And it is not preemptive management, but aimed at eliminating the consequences of the crisis that has already begun. In such situations, managers assess the potential of real estate objects, correlate the wishes of the owners and the specified performance criteria with the actual state of the market [2].

The management of commercial real estate, regardless of whether it is carried out with the involvement of management companies or without it, is a rather complex multifaceted activity. It has not yet been provided with professional knowledge, methods or standards. However, theoretical approaches to commercial real estate management can be formulated quite clearly. In this work, the terminological apparatus used in the scientific literature is studied, which contains various definitions of the concept of "real estate management". A critical analysis of these definitions made it possible to focus on the following: property management - the implementation of a set of measures to maintain a property in a working condition (including the organization of maintenance, repair and provision of the facility with the necessary resources) and its most effective use in the interests of the owner. Commercial real estate should be understood as buildings and structures with associated land plots, for which there is a possibility (limited by physical feasibility, legal 
permissibility and economic feasibility) of commercial use by organizing a business that allows generating income in the form of rental income and subsequent sale [3].

To form a mechanism for managing commercial real estate, the analysis of the essence of the concept of "mechanism" is carried out in the work, and the substantiation of the appropriateness of using this concept in the field of real estate management is provided. As part of the substantiation, an analysis of the literature covering this aspect was carried out. The mechanism is considered as the order of interaction of the system elements, which ensures the maximum achievement of the goal.

The concept of "management mechanism" is used to characterize management actions in relation to management processes. With regard to commercial real estate objects, this mechanism reflects the interactions of management blocks, and this means both interactions within the blocks and between them. Like any mechanism from the economic sphere, the mechanism for managing commercial real estate has its own organizational, economic, social and technical components. In accordance with the ideology of this study, priority is given to the organizational and economic component. The control mechanism as a system of levers and incentives that facilitate the implementation of certain actions is aimed at ensuring the possibility of making effective management decisions (hereinafter MD), which allows considering decisions as a key element of this mechanism.

It is proposed to orient this mechanism towards the formation of measures that increase the investment attractiveness of a commercial property [4].

The management process is the central link of the enlarged mechanism proposed for use. It is advisable to present it in the form of a logically built and stage-by-stage sequence of actions (Figure 1). This sequence has an implementation character. By performing a series of actions step by step, it is possible to make reasonable management decisions that transform the property and increase its investment attractiveness.

Revealing the content of each of the blocks in the algorithm presented in Figure 1, special attention is paid to the theoretical and methodological foundations of the formation of management decisions in comparison with the principles and methods of formation of measures to transform the object. At the same time, the following conclusions were formulated:

1. Management decisions always correspond to the goals of the planned transformations.

2. From the point of view of organization and management, the goals of transformation and the goals of management coincide.

3. Management decisions are formed, substantiated and adopted on the same fundamental basis as the formation of activities (many options and selection criteria are needed). However, it means that we are not talking about choosing actions to transform an object, but about choosing ways to implement these actions. The effectiveness of a manager's activity is determined not only by planning rational transformations, but also by their effective implementation.

An assessment of the investment attractiveness of commercial real estate objects should be carried out from the standpoint of an organization participating in the creation, operation and development of this object. The assessment should be carried out taking into account the dynamics of factors of the external and internal environment. To assess the investment attractiveness of commercial real estate, the factors are structured and indicators are proposed, on the basis of which assessment procedures should be carried out. The factors are considered in three broad groups: factors that describe the parameters of real estate; cost factors; factors of the development process. In the detailed structuring, the factors are considered from the standpoint of their influence on the investment attractiveness of the object. 


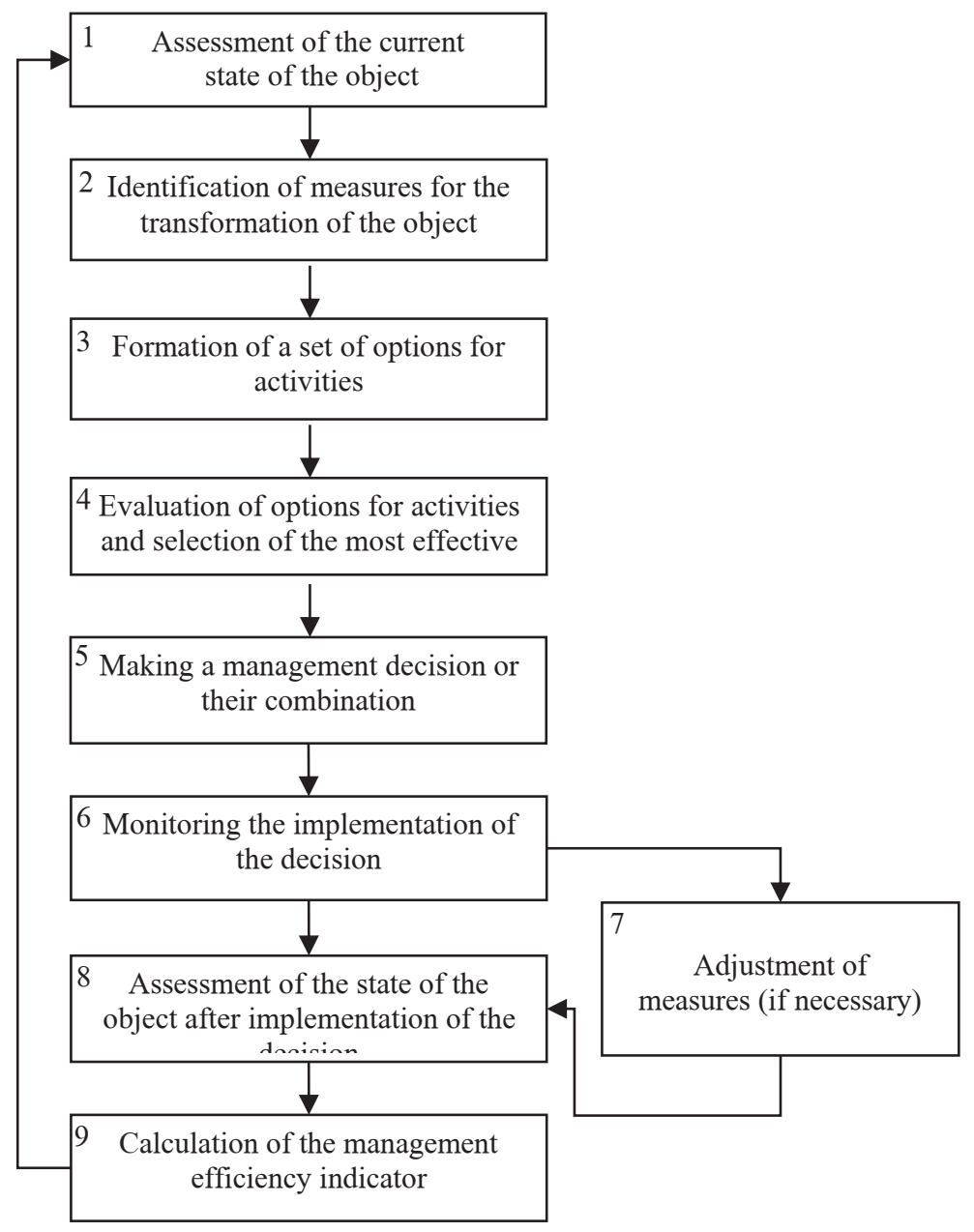

Fig. 1. The sequence of stages in the control process

Three levels are highlighted at which various factors are located. The first level deals with the physical characteristics of the building; characteristics of the land plot attributed to the object; entrance to the building, legal support [5]. The second level analyzes the factors reflecting the attractiveness of the neighboring environment of the object. These include the characteristics of the location, the degree of development of the area and neighboring facilities, transport infrastructure, engineering infrastructure, as well as engineering and geological conditions. The third level combines the factors of attractiveness of the external environment, region, market. Among them - the situation on the real estate market, conditions for land use, administrative regulation, general economic and socio-political situation, natural factors $[6,7]$.

\section{Results}

Due to the large number and uncertainty of the presented factors, it is recommended to assess them using an integral indicator, which can be determined on the basis of rating estimates. When determining the weight coefficients reflecting the degree of influence of 
the factors that determine the investment attractiveness of commercial real estate, the expert method was used. Professional participants of the real estate market with experience in working with commercial real estate were involved as experts.

The paper developed an algorithm for assessing the investment attractiveness of commercial real estate, which can be represented as a sequence of the following stages:

1) a vector of initial factors is formed, each of which is necessary, and all of them together are sufficient for a complete, comprehensive assessment of the investment attractiveness of commercial real estate according to formula 1 :

where $\mathrm{X}$ - vector of initial factors;

$$
\mathrm{X}=(\mathrm{X}(1), \ldots, \mathrm{X}(15)) \text {, }
$$

$\mathrm{X}$ (i) - factors characterizing the investment attractiveness of commercial real estate;

$\mathrm{i}$ - commercial real estate investment attractiveness factor index $(i=1, \ldots, 15)$;

$\mathrm{i}=1, \ldots, 4$ - factors of attractiveness of the property itself and the surrounding area (1st level);

$\mathrm{i}=5, \ldots, 9$ - factors of attractiveness of the neighborhood environment of real estate ( 2 nd level);

$\mathrm{i}=10, \ldots, 15$ - factors of attractiveness of the external environment of real estate ( $3 \mathrm{rd}$ level);

2) a vector of individual indicators is constructed, which are functions of the initial factors, which make it possible to quantify the factors of attractiveness using scores according to formula 2 :

$$
\mathrm{q}=(\mathrm{q}(1), \ldots, \mathrm{q}(15)) \text {, }
$$

where q ( $i$ ) - the function of the corresponding initial characteristic, which determines the degree of manifestation of the analyzed factor, expressed as a score q (i) $=q(X$ (i)), according to the specified conditions, takes the values - $0,1,2,3$;

q (i) $=0$ corresponds to the minimum degree of manifestation of the factor;

$q(i)=3$ corresponds to the maximum degree of manifestation of the factor.

3) a synthesizing function is constructed that compares the vector of individual indicators $\mathrm{q}$ with a consolidated quantitative assessment characterizing the overall assessment of the investment attractiveness of an object, taking into account the weight coefficients of the significance of factors according to formula 3 :

$$
Q(q ; w)=q(1) \times(1)+, \ldots,+q(15) \times w(15)
$$

where Q - summary quantitative assessment of the indicator of investment attractiveness of commercial real estate;

w ( i ) - weight coefficient that determines the relative importance of investment attractiveness factors, determined by expert.

In this case, according to the weight coefficient, the following restrictions are adopted:

$$
w(i)>0 \quad \text { and } \quad \sum_{i=1}^{15} w(i)=1
$$

To concretize the mechanism for managing commercial real estate, the work formulates recommendations for the formation of appropriate management decisions. At the same time, the principles of MD formation have been studied, including the principles of consistency, goal-setting, variance of alternatives, hierarchy, criteria-based choice, timeliness, optimality, as well as a set of methods used to substantiate decisions and their functions. Based on the assertion that the central link in the mechanism for managing commercial real estate is the process of forming a number of measures and the adoption of $\mathrm{MD}$, the following thesis was formed: both the development of measures and the development of MD have the same economic nature. Both are based on the provisions of 
the systematic approach and should be justified taking into account the principle of plurality and the need for choice.

The process of forming activities and making realizable management decisions is also algorithmized and presented as a sequence of eight stages (Figure 2).

The efficiency of increasing investment attractiveness $(E g r$. $)$ is calculated by formula 4:

$$
E g r=Q_{0} / Q_{b * 100-100}
$$

where $\mathrm{Q}_{0}$ - indicator of investment attractiveness, determined after carrying out measures (one or more) to increase the investment attractiveness of real estate;

$Q_{b}$ - indicator of investment attractiveness, determined before the measures to increase the investment attractiveness of real estate.

1) assessment of the indicator of investment attractiveness of existing commercial real estate objects

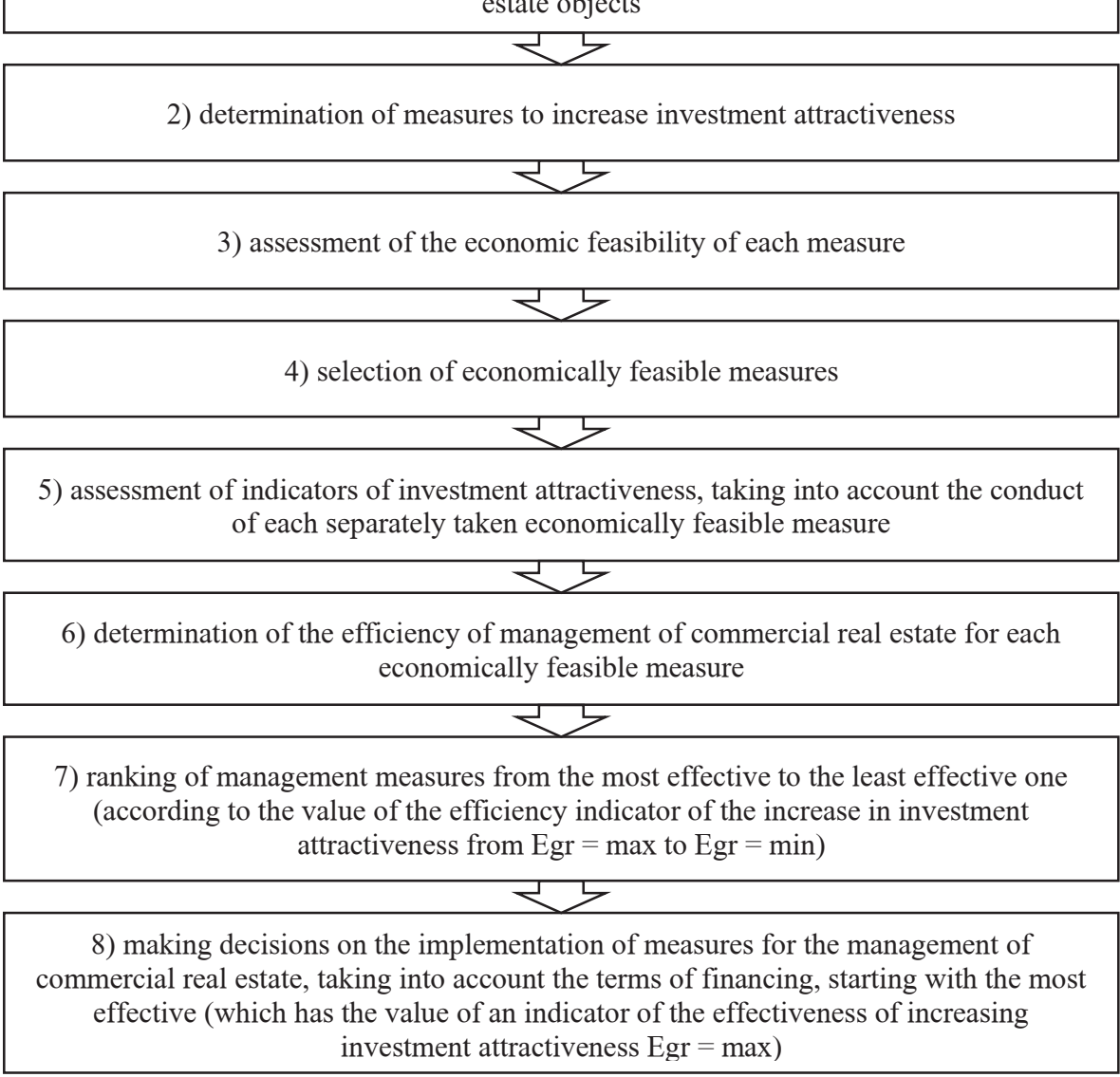

Fig. 2. The process of forming measures and making realizable management decisions

\section{Discussions}

The developed mechanism for managing commercial real estate objects, equipped with appropriate methods and algorithms, allows not only assessing the effectiveness of each measure to transform a specific object, but also justifying the implementation of management decisions. This will help with minimal costs and maximum effect to manage 
commercial real estate objects from the position of the owner, which ultimately will contribute to the renovation of commercial real estate used for various needs.

\section{Conclusion}

As a result of the study, a scientific analysis of the processes and trends observed in the real estate market and in the sector related to commercial real estate was carried out; the principles, methods and established practice of professional management in the field of real estate are characterized; specifics of the activities of management companies and the prospects for professional real estate management are specified; the principles, methods and approaches to the development of management decisions in the field of commercial real estate, which requires specific measures to transform objects, are studied; an algorithm for the formation of activities and realizable management decisions has been developed.

\section{References}

1. M. Tetik, A. Peltokorpi, O. Seppänen, J. Holmström, Automation in Construction, 107, 102910 (2019)

2. Kovalenko, K. E., Bakhvalov, S. Y., Zekiy, A. O., Vikulina, V. V., Tinkov, S. A., \& Tkacheva, T. V. (2019). Key indicators of innovation activity of Russia (from 2011 to 2017). Journal of Entrepreneurship Education, 22(3), 1-7

3. R. Golov, M. Pushkareva, E3S Web Conf., 110 (2019) https://doi.org/10.1051/e3sconf/201911002134.

4. O.J. Kravets, E.S. Podvalny, S.A. Barkalov, Automation and Remote Control, 76(3) 500-506 (2015)

5. V. Poryadina, V. Burkov, S. Barkalov, I. Ilin, O. Kalinina, MATEC Web of Conferences conference proceedings, 01122 (2018)

6. Konina, O.V., Tinkov, S.A., Tinkova, E.V. Management in Higher Education Based on "Smart Technologies": Digital Managerial Staff vs. Artificial Intelligence. Lecture Notes in Networks and Systems, 2021, DOI: 10.1007/978-3-030-59126-7_190

7. S. A. Tinkov, E. V. Tinkova, Indicator to Assess the Level of Development of Productive Capacity and Quality of Life. In: Solovev D. (eds) Smart Technologies and Innovations in Design for Control of Technological Processes and Objects: Economy and Production. FarEastCon 2018. Smart Innovation, Systems and Technologies, Springer, Cham., 139 (2019) https://doi.org/10.1007/978-3-030-18553-4_69 